\section{GLYCEROLYSIS USING KF/CAO-MGO CATALYST: OPTIMISATION AND REACTION KINETICS}

Luqman Buchori*, Mohammad Djaeni, R. Ratnawati, Diah Susetyo Retnowati, H. Hadiyanto, Didi Dwi Anggoro
Article history

Received

22 January 2020

Received in revised form

22 July 2020

Accepted

27 July 2020

Published online

27 August 2020

\section{*Corresponding author \\ luqman.buchori@che.undip.ac.id}

Department of Chemical Engineering, Faculty of Engineering, Diponegoro University, Jl. Prof. Soedarto, SH Tembalang, Semarang, 50275, Indonesia

\section{Graphical abstract}
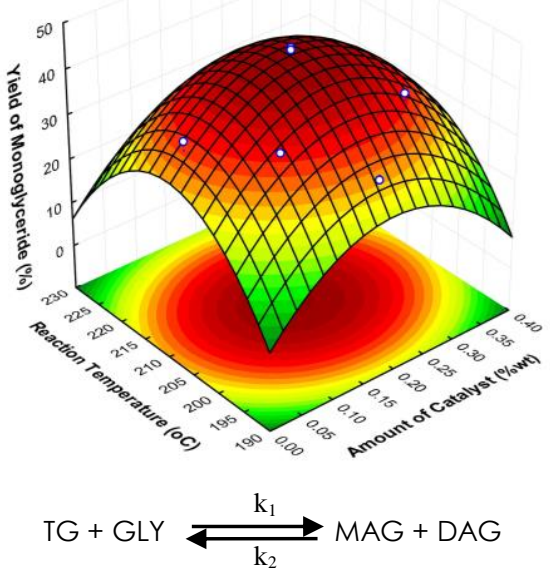

\begin{abstract}
Monoglycerides can be produced through glycerolysis using a heterogeneous catalyst. The purpose of this study is to analyse the optimum conditions for the production of monoglycerides from glycerol and cooking oil using $\mathrm{KF} / \mathrm{CaO}-\mathrm{MgO}$ base catalysts and to investigate the kinetics of the monoglyceride glycerolysis reaction. The response surface method (RSM) was used to determine the favourable conditions by varying the catalyst amount $\left(X_{1}\right)$ between $0.1,0.2$ and $0.3 \%(\mathrm{w} / \mathrm{W})$; the reaction temperature $\left(\mathrm{X}_{2}\right)$ between 210,220 and $230^{\circ} \mathrm{C}$ and reaction time $\left(X_{3}\right)$ between 2,3 and 4 hours. Gas chromatography-mass spectrometry (GC-MS) was used to determine the monoglycerides, while catalysts were characterised by X-ray diffraction (XRD) and the BrunauerEmmett-Teller method (BET). The results showed that, among the three factors examined, temperature shows the most control over this glycerolysis reaction. The most favourable conditions are $X_{1}=0.19 \%(w / w), X_{2}=208.37^{\circ} \mathrm{C}$ and $X_{3}=3.20$ hours, which provide a monoglyceride yield of $41.58 \%$. The constants for the reaction kinetics of the monoglyceride formation, $k_{1}$ and $k_{2}$ are 1.04189 and

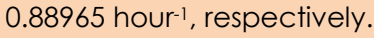

Keywords: Glycerolysis, monoglyceride, kinetics, KF/CaO-MgO catalyst, RSM optimisation

\subsection{INTRODUCTION}

Glycerolysis is the reaction of glycerol with triglycerides (fats/oils) to form mono-acyl glycerol (MAG) and di-acyl glycerol (DAG). Monoacylglycerol $(M A G) / m o n o g l y c e r i d e s(M G)$ are widely used as surfactants and emulsifiers in food, cosmetics and pharmaceutical products [1]. In the food industry, the consumption of MAG/MG reaches $75 \%$ of the total emulsifying production. Specifically, monoglycerides are used for the productions of bakery products, margarine, dairy products and confectionary [2]. Additionally, they can be used as synthetic constituents and plasticisers [3,4].
Glycerolysis can be carried out with or without a catalyst. The catalyst simply accelerates the reaction by directing $\mathrm{OH}$ groups to MAG formation. The reaction can be carried out with either of two methods: chemical synthesis (using acid, basic, or metal oxide catalysts), or enzymatic synthesis (using lipase catalysts) [5]. Compared to chemical synthesis, enzymatic synthesis has several advantages including mild reaction conditions, higher yields and lower energy consumption [6]. However, enzymatic synthesis is more complex, time-consuming, expensive and the enzymes are difficult to separate from the product $[2,5]$. In contrast, chemical synthesis has a short reaction period [7]. Base 
catalysts are more widely used than acid catalysts because the reaction time is faster, the reaction is non-corrosive and it produces higher yields [8]. Most often, the reaction proceeds under alkaline conditions and the most frequently used base catalysts include $\mathrm{NaOH}$ [9], $\mathrm{NaOCH}_{3}$ [10], $\mathrm{CaO}$ [11] and $\mathrm{MgO}$ [3]. However, pure base catalysts, especially metal oxides, have lower catalyst activities compared to mixed metal oxides [12].

The use of impregnated mixed metal oxide catalysts, $\mathrm{KF} / \mathrm{CaO}-\mathrm{MgO}$ catalyst in particular, in the glycerolysis reaction has not been investigated yet. Impregnating the supporting material with a solid metal oxide catalyst has many advantages such as increased catalyst surface area, high monoglyceride selectivity, environmentally friendly, easy catalyst separation and inexpensive product-purification processes [13]. Since this catalyst shows great potential, it is important to explore its use in glycerolysis.

The glycerolysis reaction between glycerol and oil is a multiphase reaction. It is carried out at high temperature $\left(250^{\circ} \mathrm{C}\right)$ in order to increase the solubility of glycerol in the oil, which is only around $4 \%$ at room temperature [14]. Due to the multiphase properties of the sample, studies of the kinetics of the glycerolysis reaction between glycerol and triglycerides have not been carried out.

The present study aims to determine the optimum conditions and the corresponding reaction rate constants of the glycerolysis reaction between glycerol and triglycerides. Optimisation is carried out using the response surface method (RSM) with the Statistica software version 12.0 concerning the catalyst amount $\left(X_{1}\right)$, reaction temperature $\left(X_{2}\right)$ and reaction time $\left(X_{3}\right)$. The reaction kinetics is solved using the fourth-order Runge-Kutta.

\subsection{METHODOLOGY}

\subsection{Materials}

In this research, the $\mathrm{KF} / \mathrm{CaO}-\mathrm{MgO}$ catalyst was made using potassium fluoride (KF), magnesium acetate, absolute ethanol (99.9\%), calcium nitrate $\left(\mathrm{Ca}\left(\mathrm{NO}_{3}\right)_{2}\right)$ and citric acid from Merck (Germany). Tropical cooking oil that is a source of triglycerides was acquired from a supermarket and glycerol (85\%) was obtained from Merck.

\subsection{Preparation of KF/CaO-MgO Catalyst}

The KF/CaO-MgO catalyst was prepared in two steps. First, we prepared the CaO-MgO catalyst, which was then impregnated with KF. In the first step, the preparation of $\mathrm{CaO}-\mathrm{MgO}$ catalysts was carried out by dissolving magnesium acetate, calcium nitrate and citric acid into a $95 \%$ ethanol solution and stirring until the solution became homogeneous (clear coloured). The mixed solution was then stirred at a speed of $300 \mathrm{rpm}$ while being heated to form a sol. Heating was continued while stirring up to $80^{\circ} \mathrm{C}$ and a gel was formed. The formed gel was dried in an oven at $110^{\circ} \mathrm{C}$ overnight. The dry solid was then calcined in a Ney Vulcan box furnace at $550^{\circ} \mathrm{C}$ for 3 hours. The obtained solid product was a $\mathrm{CaO}-\mathrm{MgO}$ catalyst.

The second step was the impregnation of the $\mathrm{CaO}-\mathrm{MgO}$ catalyst with the KF solution. Two percent of KF was dissolved in aquadest. Impregnation was carried out by immersing the $\mathrm{CaO}-\mathrm{MgO}$ catalyst in the KF solution for one hour while stirring, followed by drying in an oven (Memmert) at $140^{\circ} \mathrm{C}$ for 6 hours. The dried solid catalyst was then calcined at 450, 500 and $550^{\circ} \mathrm{C}$ in a box furnace for 3 hours. The resulted solid catalyst was called KF/CaO-MgO.

\subsection{Characterisation of Catalyst and Product}

The catalyst was characterised through X-ray diffraction (XRD) and the Brunaver-Emmett-Teller (BET) surface area method (ChemBET PULSAR Quantachrome). XRD analysis was carried out using a ShimadzU XRD-7000. The XRD patterns were measured under $\mathrm{Cu}-\mathrm{K} \alpha$ radiation conditions ( $\mathrm{k}=1.54$ $\AA)$ at $30 \mathrm{~mA}$ and $40 \mathrm{kV}$. The diffraction pattern was produced in an angle range of $2 \theta$ from $10^{\circ}$ to $70^{\circ}$ with a step size of 0.017 and a step time of 0.5 seconds. The diffractogram/peak obtained was compared with data from the JCPDS library (Joint Committee on Powder Diffraction Standards).

The surface area of the catalyst was measured using nitrogen adsorption at $77.15 \mathrm{~K}$. 0.2 grams of the sample were degassed with nitrogen gas under vacuum for 1 hour at $200^{\circ} \mathrm{C}$ before the absorption measurements.

The monoglyceride products were analysed using gas chromatography-mass spectrometry (GC-MS) (QP2010S SHIMADZU, DB-1 column). GC-MS was also used to determine the molecular weight of the compound. In GC-MS, the sample was analysed at an oven temperature of $50^{\circ} \mathrm{C}$ (5 minutes). The temperature was raised by $10^{\circ} \mathrm{C} / \mathrm{min}$ up to $260^{\circ} \mathrm{C}$ and subsequently held there for 33 minutes.

\subsection{Glycerolysis}

The formation of monoglycerides was achieved using oil (triglyceride)-to-glycerol molar ratio of 1 to 3 . The catalyst, which had been calcined at $550^{\circ} \mathrm{C}(\%$ by weight), was dissolved in glycerol at $90^{\circ} \mathrm{C}$ in a glass vessel and stirred until the solution was completely homogeneous. Afterward, the triglyceride was placed in a glass vessel and heated to $150^{\circ} \mathrm{C}$ while stirring. Once the oil reached the feed temperature, the mixture of glycerol and catalyst was gradually added while stiring. During the mixing process, the temperature was maintained stable at $150^{\circ} \mathrm{C}$. The operating conditions were varied according to the optimisation variable. The product was separated from the residue and analysed using GC-MS. The 
monoglyceride (MAG) yield was calculated using Equation (1).

Yield $_{\text {MAG }}(\%)=\frac{\text { weight of product }(g)}{\text { weight of cooking oil }(g)} \times \%$ com position MAG (1)

The reaction rate kinetics was determined by varying the reaction time from 1 to 5 hours with a batch system based on the operating conditions' optimisation results.

\subsection{Experimental Design}

In order to determine the effect of the response variables on the glycerolysis reaction, we designed the experiment based on the principles of central composite design (CCD) and using the RSM. This approach is widely used to design second-order models. Second-order polynomial models were used to verify the effect and interactions of the linear and quadratic of the process variables [15]. By applying a CCD, the effect of each parameter can be evaluated quickly and effectively [16]. The experimental design was used to establish the low, centre and high values of the catalyst amount $(\%$ $\mathrm{w} / \mathrm{w})$, the reaction temperature and the reaction time. Table 1 shows the experimental design.

The experimental design for optimisation had 16 runs and the experiments were carried out to obtain the optimal monoglyceride results (Table 2).
Table 1 Range and level of independent variables for RSM

\begin{tabular}{|c|c|c|c|c|}
\hline \multirow[b]{2}{*}{ Variables } & \multirow[b]{2}{*}{ Unit } & \multicolumn{3}{|c|}{ Variable Level } \\
\hline & & $\begin{array}{c}\text { Low } \\
\text { level } \\
(-1)\end{array}$ & $\begin{array}{c}\text { Centre } \\
\text { level } \\
(0)\end{array}$ & $\begin{array}{c}\text { High } \\
\text { level } \\
(+1)\end{array}$ \\
\hline Catalyst amount $\left(X_{1}\right)$ & $\%(w / w)$ & 0.1 & 0.2 & 0.3 \\
\hline Reaction temperature $\left(\mathrm{X}_{2}\right)$ & ${ }^{\circ} \mathrm{C}$ & 200 & 210 & 220 \\
\hline Reaction time $\left(X_{3}\right)$ & Hours & 2 & 3 & 4 \\
\hline
\end{tabular}

The Statistica software version 12.0 was used to analyse the experimental data and was installed into the second-order polynomial equations. The interaction between the dependent and independent variables was achieved through Equation (3) [17].

$$
\begin{gathered}
Y=f\left(X_{1}, X_{2}, \ldots, X_{k}\right)+\varepsilon \\
i=1,2,3, . k \\
Y=\beta_{0}+\sum_{i=1}^{k} \beta_{i} X_{i}+\sum_{i=1}^{k} \beta_{i i} X_{i}^{2}+\sum \sum_{i<j} \beta_{i j} X_{i} X_{j}+\varepsilon
\end{gathered}
$$

where $Y$ is the observed response, $\beta_{0}$ is a regression parameter, $\beta_{i}$ is the linear effect, $\beta_{i i}$ is the quadratic effect, $\beta_{i j}$ is the interaction effect, $X_{i}$ is the main linear variable, $X_{i} X_{j}$ are two linear variables, $X_{i}^{2}$ is the square of the main variable and $\varepsilon$ is the random error between the predicted and the measured values.

Table 2 RSM for three independent variables in the corresponding values and code unit

\begin{tabular}{ccccccc}
\hline & \multicolumn{3}{c}{ Independent variables } & \multicolumn{3}{c}{ Coded variables } \\
\cline { 2 - 7 } Run & Catalyst Amount $(\% \mathbf{w} / \mathbf{w})$ & Reaction Temperature $\left({ }^{\circ} \mathbf{C}\right)$ & Reaction Time (Hours) & $\mathbf{X}_{1}$ & \multicolumn{1}{c}{$\mathbf{X}_{2}$} & \multicolumn{1}{c}{$\mathbf{X}_{3}$} \\
\hline 1 & 0.10 & 200.00 & 2.00 & -1.00 & -1.00 & -1.00 \\
2 & 0.10 & 200.00 & 4.00 & -1.00 & -1.00 & 1.00 \\
3 & 0.10 & 220.00 & 2.00 & -1.00 & 1.00 & -1.00 \\
4 & 0.10 & 220.00 & 4.00 & -1.00 & 1.00 & 1.00 \\
5 & 0.30 & 200.00 & 2.00 & 1.00 & -1.00 & -1.00 \\
6 & 0.30 & 200.00 & 4.00 & 1.00 & -1.00 & 1.00 \\
7 & 0.30 & 220.00 & 2.00 & 1.00 & 1.00 & -1.00 \\
8 & 0.30 & 220.00 & 4.00 & 1.00 & 1.00 & 1.00 \\
9 & 0.03 & 210.00 & 3.00 & -1.68 & 0.00 & 0.00 \\
10 & 0.37 & 210.00 & 3.00 & 1.68 & 0.00 & 0.00 \\
11 & 0.20 & 193.18 & 3.00 & 0.00 & -1.68 & 0.00 \\
12 & 0.20 & 226.82 & 3.00 & 0.00 & 1.68 & 0.00 \\
13 & 0.20 & 210.00 & 1.32 & 0.00 & 0.00 & -1.68 \\
14 & 0.20 & 210.00 & 4.68 & 0.00 & 0.00 & 1.68 \\
15 & 0.20 & 210.00 & 3.00 & 0.00 & 0.00 & 0.00 \\
16 & 0.20 & 210.00 & 3.00 & 0.00 & 0.00 & 0.00 \\
\hline
\end{tabular}

The desired response was the monoglyceride yield. The statistical significance of the average ratio of the square variation due to regression and the mean square error residuals was tested with ANOVA 
[18]. The correlation coefficient $\left(R^{2}\right)$ was used to state the quality of the conformity of the polynomial model. The main indicators included the probability values (Prob > F), the F-values model (Fisher ratio variation) and the adequate precision indicating the adequacy and significance of the model used. Maximisation was used to determine the best and optimised local maximums. In order to do this maximisation, these indicators were combined into the function using the software.

\subsection{Kinetic Model}

The glycerolysis reaction of monoglycerides is reversible. Excessive use of glycerol is theoretically necessary to shift the equilibrium to the right so that the total monoglyceride obtained increases [19].

The reaction rate kinetics were used to estimate a constant rate for all possible reactions. This approach requires a thorough understanding of the steps in a sequential reaction. The formation of the monoglyceride equation is shown in Equations (4) to (7).

$$
\begin{aligned}
& \mathrm{TG}+\mathrm{GLY} \underset{\text { Catalyst }}{\stackrel{\mathrm{KF} / \mathrm{CaO}-\mathrm{MgO}}{\rightleftarrows}} \mathrm{MAG}+\mathrm{DAG}
\end{aligned}
$$

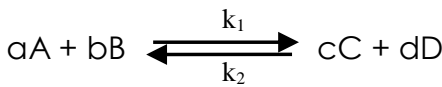

Being an equation

$$
\begin{gathered}
-r_{A}=-\frac{d C_{A}}{d t}=k_{1} C_{A} C_{B}-k_{2} C_{C} C_{D} \\
\frac{d X_{A}}{d t}=k_{1} C_{A_{0}}^{2}\left(1-X_{A}\right)\left(\theta_{B}-\theta_{A}\right)-k_{1} C_{A}^{2} X_{A}^{2}
\end{gathered}
$$

Equation (7) was solved by the fourth-order Runge-Kutta, which is used in solving problems related to numerical calculations. It is an important tool for solving differential equations with initial conditions [20].

\subsection{RESULTS AND DISCUSSION}

\subsection{Characterisation of the Catalyst}

The XRD patterns of the catalyst before and after impregnation at varied calcinations temperatures are shown in Figure 1.

The XRD pattern on the CaO-MgO catalyst before being impregnated with $\mathrm{KF}$ is presented in Figure 1 (a). The XRD pattern of the catalyst after being impregnated with $\mathrm{KF}$ at the different calcination temperatures is shown in Figure $1(b, c, d)$. In Figure 1 (a), the XRD diffractrogram shows the peaks of the $\mathrm{CaO}\left(37.36^{\circ}, 74.65^{\circ}\right.$ and $\left.78.70^{\circ}\right)$ and $\mathrm{MgO}\left(42.91^{\circ}\right.$ and $\left.62.15^{\circ}\right)$ components. After the catalyst was calcined at $450^{\circ} \mathrm{C}$, peaks corresponding to the $\mathrm{Ca}(\mathrm{OH})_{2}$ component appeared at $18.19^{\circ}, 29.39^{\circ}, 50.77^{\circ}$ and $58.74^{\circ}$. This shows that the calcination temperature of $450^{\circ} \mathrm{C}$ is low. When the calcination temperature is increased to 500 and $550^{\circ} \mathrm{C}, \mathrm{CaKF}_{3}$ and $\mathrm{MgKF}_{3}$ crystals form, which appear in the XRD patterns as new peaks. $\mathrm{CaKF}_{3}$ and $\mathrm{MgKF}_{3}$ are active sites formed due to the addition of KF as support. The presence of these crystals increases the catalyst activity and produces higher monoglyceride yields [21].

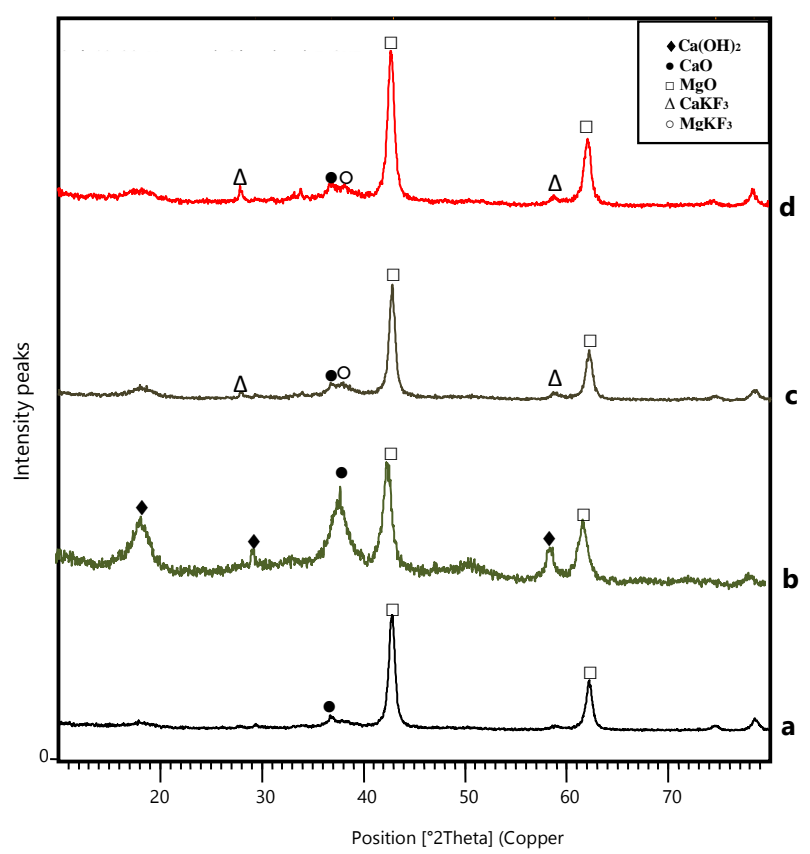

Figure 1 XRD pattern of the KF/CaO-MgO catalysts: (a) $\mathrm{CaO}-\mathrm{MgO}$ catalyst; (b) $\mathrm{KF} / \mathrm{CaO}-\mathrm{MgO}$ catalyst $\left(450^{\circ} \mathrm{C}\right)$; (c) $\mathrm{KF} / \mathrm{CaO}-\mathrm{MgO}$ catalyst $\left(500^{\circ} \mathrm{C}\right)$; (d) $\mathrm{KF} / \mathrm{CaO}-\mathrm{MgO}$ catalyst $\left(550^{\circ} \mathrm{C}\right)$

The results of the surface area characterisation are presented in Table 3.

Table 3 The surface area of the catalyst under various treatments

\begin{tabular}{cc}
\hline Catalyst & $\begin{array}{c}\text { Surface Area } \\
\left(\mathbf{m}^{2} / \mathbf{g}\right)\end{array}$ \\
\hline $\mathrm{CaO}-\mathrm{MgO}$ & 112,250 \\
$\mathrm{KF} / \mathrm{CaO}-\mathrm{MgO}\left(450^{\circ} \mathrm{C}\right)$ & 132,456 \\
$\mathrm{KF} / \mathrm{CaO}-\mathrm{MgO}\left(500^{\circ} \mathrm{C}\right)$ & 119,706 \\
$\mathrm{KF} / \mathrm{CaO}-\mathrm{MgO}\left(550^{\circ} \mathrm{C}\right)$ & 110,924 \\
\hline
\end{tabular}

Table 3 shows the increase in the catalyst surface area after impregnation with KF. However, the surface area of the catalyst decreases with increasing calcination temperature. This may be caused by aggregation of the catalyst as a result of the formation of the new active catalyst sites $\left(\mathrm{CaKF}_{3}\right.$ and $\mathrm{MgKF}_{3}$ ) that occurs at high calcination temperatures. However, the formation of $\mathrm{CaKF}_{3}$ and $\mathrm{MgKF}_{3}$ increase the catalyst activity. Indeed, the increase in the calcination temperature to 500 and $550^{\circ} \mathrm{C}$ forms new crystals (Figure 1), namely $\mathrm{CaKF}_{3}$ 
$\left(28.28^{\circ}\right.$ and $\left.59.32^{\circ}\right)$ and $\mathrm{MgKF}_{3}\left(38.58^{\circ}\right) . \mathrm{KF}$ addition to heterogeneous catalysts and high calcination temperatures produce new crystals (such as $\mathrm{CaKF}_{3}$ and $\mathrm{MgKF}_{3}$ ) as active sites that can produce higher yields due to the high catalytic activity [21].

Based on the characterisation of this catalyst, the catalyst used for the glycerolysis process is $\mathrm{KF} / \mathrm{CaO}$ $\mathrm{MgO}$, which is calcined at $550^{\circ} \mathrm{C}$.

\subsection{Model Fitting}

According to the experimental design, 16 experimental runs were carried out according to the optimisation variables (the catalyst amount, the reaction temperature and the reaction time), as shown in Table 2. The experimental data were fitted to the polynomial equation to quantify the curvature effects [18]. The second-order fitting polynomial equation of the coded factors was expressed as shown in Equation (8).

$$
\begin{aligned}
& Y=-2750.60+299.09 X_{1}-434.98 X_{1}^{2}+25.08 X_{2} \\
& -0.06 X_{2}^{2}+98.58 X_{3}-4.57 X_{3}^{2}-0.14 X_{1} X_{2} \\
& -9.92 X_{1} X_{3}-0.33 X_{2} X_{3}
\end{aligned}
$$

The complete 16 sets of the experimental design matrix and the experimental and predicted values of the yield of monoglycerides proposed by CCD are tabulated in Table 4 [16]. Table 4 also shows the raw and absolute residual values, as well as the percentage of error responses for all batches. The model is verified by comparing the experimental with the predictive values (Figure 2). Indeed, the obtained monoglyceride yield varies between 27.58 to $46.33 \%$ and the values predicted by the model match the experimental results satisfactorily.

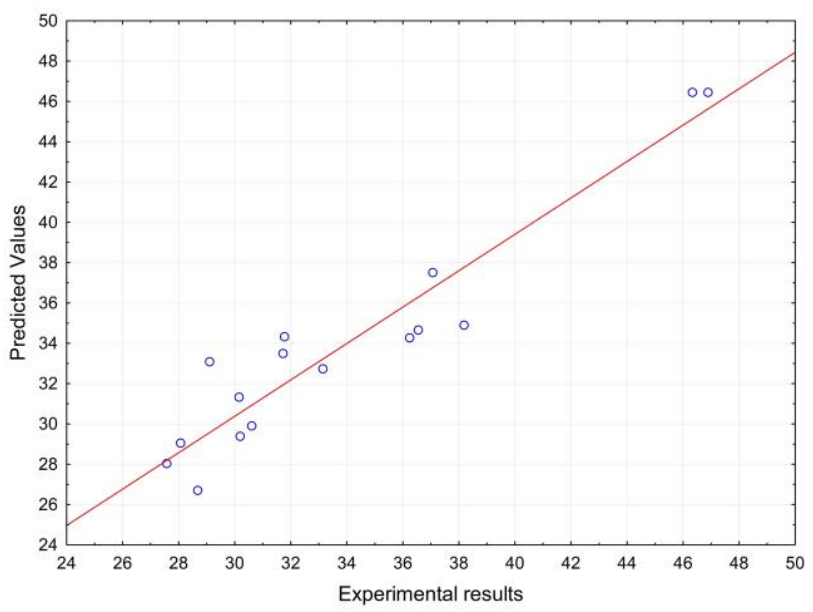

Figure 2 Predicted and experimental values for monoglyceride yield

\subsection{Statistical Analysis Results}

ANOVA using Statistica software version 12.0 was used to appropriately assess the polynomial model (Equation (8)) taking into account the interactions [22]. Fisher F-test, where F-value is the ratio between the squares of the regression and the average error, was used to determine the statistical significance of the factor to the response. The ANOVA results for the percentage of monoglycerides are presented in

\begin{tabular}{|c|c|c|c|c|c|}
\hline \multirow{2}{*}{ Run } & \multicolumn{2}{|c|}{ Yield of monoglycerides } & \multirow{2}{*}{$\begin{array}{c}\text { Raw } \\
\text { residuals }\end{array}$} & \multirow{2}{*}{$\begin{array}{c}\text { Error } \\
(\%)\end{array}$} & \multirow{2}{*}{$\begin{array}{l}\text { Absolute } \\
\text { residuals }\end{array}$} \\
\hline & Experimental & Predicted & & & \\
\hline 1 & 27.580 & 28.042 & -0.46 & -1.67 & 0.46 \\
\hline 2 & 37.070 & 37.513 & -0.44 & -1.19 & 0.44 \\
\hline 3 & 31.720 & 33.504 & -1.79 & -5.64 & 1.79 \\
\hline 4 & 30.610 & 29.903 & 0.71 & 2.32 & 0.71 \\
\hline 5 & 30.190 & 29.381 & 0.81 & 2.68 & 0.81 \\
\hline 6 & 38.190 & 34.892 & 3.30 & 8.64 & 3.30 \\
\hline 7 & 36.240 & 34.284 & 1.95 & 5.38 & 1.95 \\
\hline 8 & 28.680 & 26.711 & 1.97 & 6.87 & 1.97 \\
\hline 9 & 36.550 & 34.664 & 1.89 & 5.17 & 1.89 \\
\hline 10 & 29.100 & 33.090 & -3.99 & -13.71 & 3.99 \\
\hline 11 & 30.160 & 31,332 & -1.17 & -3.88 & 1.17 \\
\hline 12 & 28.070 & 29.037 & -0.97 & -3.46 & 0.97 \\
\hline 13 & 33.150 & 32.737 & 0.41 & 1.24 & 0.41 \\
\hline 14 & 31.770 & 34.337 & -2.57 & -8.09 & 2.57 \\
\hline 15 & 46.890 & 46.449 & 0.44 & 0.94 & 0.44 \\
\hline 16 & 46.330 & 46.448 & -0.12 & -0.26 & 0.12 \\
\hline
\end{tabular}
Table 5.

Table 4 Experimental and predicted monoglyceride yield using RSM

The results of the analysis of variance on monoglyceride production gave an $\mathrm{R}^{2}$ of $90.28 \%$. This indicates that $90.28 \%$ of the data in the CCD can be explained by the response surface model. The effect of the variables on the response value can be expressed by the model which can then predict the maximum response value in subsequent optimisation experiments. The model results that the three 
optimisation variables (catalyst amount, reaction temperature and reaction time) have an effect greater than $90 \%$.

Table 5 ANOVA for the percentage of monoglycerides

\begin{tabular}{ccccc}
\hline Factors & $\begin{array}{c}\text { Regression } \\
\text { Coeff. }\end{array}$ & DF & F-value & p-value \\
\hline$X_{0}$ & -2750.60 & & & \\
$X_{1}$ & 299.09 & 1 & 0.1798 & 0.3469 \\
$X_{11}$ & -434.98 & 1 & 4.3462 & 0.0038 \\
$X_{2}$ & 25.08 & 1 & 0.4030 & 0.0009 \\
$X_{22}$ & -0.06 & 1 & 9.5630 & 0.0010 \\
$X_{3}$ & 98.58 & 1 & 0.1970 & 0.0049 \\
$X_{33}$ & -4.57 & 1 & 4.7694 & 0.0033 \\
$X_{12}$ & -0.14 & 1 & 0.0103 & 0.8957 \\
$X_{13}$ & -9.92 & 1 & 0.5020 & 0.3778 \\
$X_{23}$ & -0.33 & 1 & 5.4493 & 0.0201 \\
Erorr & 8.6933 & 6 & & \\
$R^{2}$ & 0.9028 & & & \\
\hline
\end{tabular}

Based on the ANOVA, the F-value obtained by the model is 60.45, which is greater than the tabulated F-value of 3.49. This F-value shows a statistically significant regression at a significance level of 5\% [23]. Therefore, the Fisher variance ratio calculated at this level is large enough to justify the very high degree of adequacy of the quadratic model and also to exhibit that the combination of treatments is very significant [24]. All p-values of monoglyceride production data produce a degree of significance $\alpha<5 \%$, except $X_{1}, X_{12}$ and $X_{13}$, indicating that the variable has a significant impact on the model.

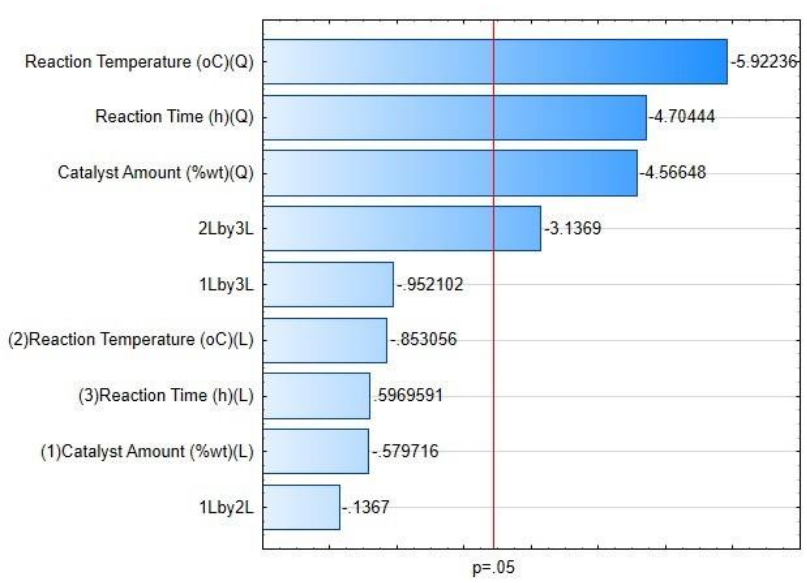

Figure 3 Pareto chart for variables that have a significant effect on the glycerolysis process

The variables that have the most significant effect are presented in Figure 3 (Pareto chart). Temperature has the most significant effect compared to the other variables.

\subsection{Optimisation Analysis}

The optimum conditions for the synthesis of monoglycerides are predicted using the optimisation function. The empirical model derived from the RSM method can be used to describe accurately the relationship between the factors and the response in the conversion of monoglycerides [19].

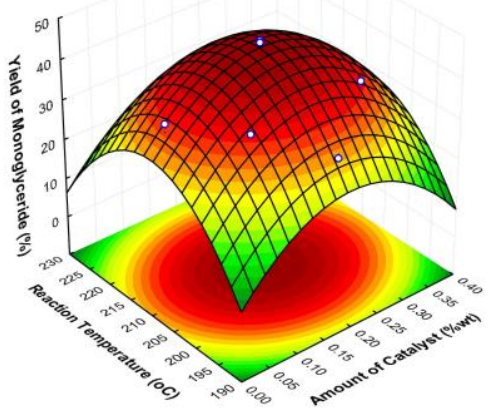

Figure $43 \mathrm{D}$ surface plots showing the interaction between catalyst amount $\left(X_{1}\right)$ with reaction temperature $\left(X_{2}\right)$ at a reaction time $\left(X_{3}\right)$ of 3 hours for monoglycerides production

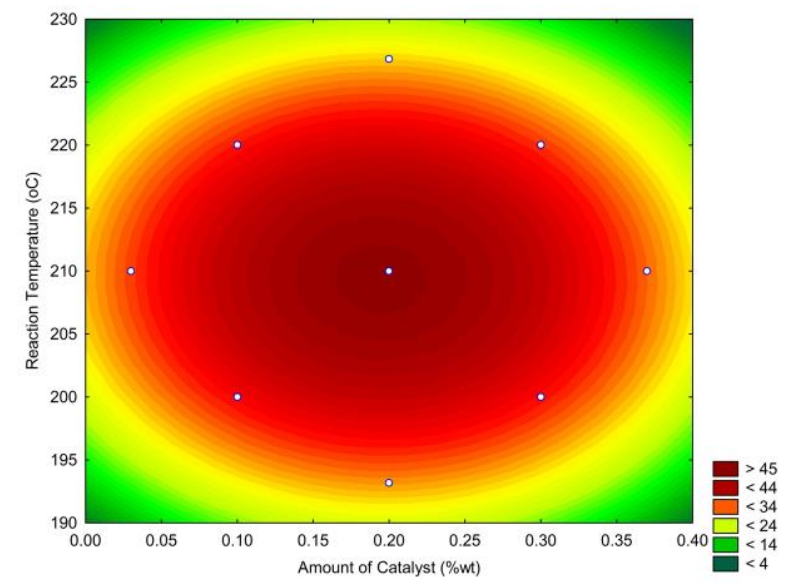

Figure $52 \mathrm{D}$ contour plot showing the interaction between the catalyst amount $\left(X_{1}\right)$ with reaction temperature $\left(X_{2}\right)$ at a reaction time $\left(X_{3}\right)$ of 3 hours for monoglyceride production

Figures 4 and 5 show $3 \mathrm{D}$ and $2 \mathrm{D}$ graphs of the response surface and contour plots of the effect that the catalyst amount has on the reaction temperature. The relationship between the catalyst amount (\% wt) and the reaction temperature in a monoglyceride product has a maximum stationary area. This is because it is necessary to carefully determine the range of data selection codes (points $-1,0,1)$ in order to attain the optimal point [25]. The 
optimal conditions derived from the Statistica software are shown in Table 6.

Table 6 Optimal values of parameters

\begin{tabular}{lc}
\hline Parameters & Optimum value \\
\hline Yield of Monoglyceride (\%) & 41.58 \\
Catalyst Amount $(\% \mathrm{w} / \mathrm{W})$ & 0.19 \\
Reaction Temperature $\left({ }^{\circ} \mathrm{C}\right)$ & 208.37 \\
Reaction Time (hours) & 3.20 \\
\hline
\end{tabular}

\subsection{Kinetics}

The optimisation results obtained are used to determine the reaction kinetics. Figure 6 indicates the effect of the reaction time on the obtained monoglyceride concentration.

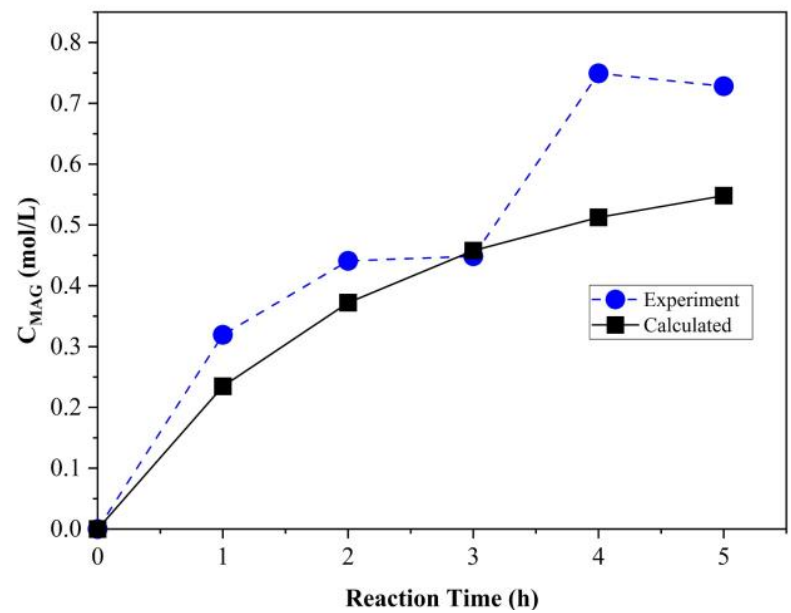

Figure $\mathbf{6}$ The relationship between the reaction time and the obtained MAG (monoacylglycerol/monoglyceride) concentration based on the experimental results and the model calculations

Figure 6 shows the difference between the experimental and modelled monoglyceride concentrations. In the experiment, the monoglyceride concentration is not stable, whereas the calculated concentration using the model is more consistent and tends to increase. Additionally, in the experiment, monoglycerides decrease after five hours reaction time. This is because once the production of monoglycerides is optimum, it is influenced by the side reactions and forms di-acyl glycerol (DAG) [26].

The computational results using the fourth-order Runge-Kutta method indicate that the reaction rate constants $k_{1}>k_{2}$ and $k_{2}>0$, with $k_{1}=1.04189$ hour $^{-1}$ and $k_{2}=0.88965$ hour $^{-1}$. Figure 7 shows the conversion results obtained by calculating the reaction rate. The coefficient of determination $\left(\mathrm{R}^{2}\right)$ is 0.936 , obtained based on the relationship between the reaction time and the conversion.



Figure 7 The conversion value of $X_{A}(\%)$ to the reaction time (hour) in monoglyceride production

\subsection{CONCLUSION}

The results obtained from the optimisation using the RSM method show that temperature has the most dominant influence with a $p$-value of 0,0009 and $R^{2}$ 0.9028 . The catalyst amount and the reaction time have lesser, yet significant, influence. Besides, the optimum reaction conditions are $X_{1}$ (catalyst amount) $=0.19 \%(\mathrm{w} / \mathrm{w}), \mathrm{X}_{2}$ (reaction temperature) $=$ $208.37^{\circ} \mathrm{C}$ and $X_{3}$ (reaction time) $=3.20$ hours with a monoglyceride content of $41.58 \%$. Based on the experimental results and calculations using the fourth-order Runge-Kutta method, monoglyceride conversion tends to decrease after five hours of reaction time. The reaction rate constants are $\mathrm{k}_{1}>\mathrm{k}_{2}$ and $\mathrm{k}_{2}>0 \mathrm{k}_{1}=1.04189$ hour-1 $^{-1}$ and $\mathrm{k}_{2}=0.88965$ hour $^{-1}$. The obtained determinant value $\left(R^{2}\right)$ is 0.936 .

\section{Acknowledgement}

This research was financially supported by the Faculty of Engineering, Diponegoro University, Indonesia through Strategic Research Grant 2019.

\section{References}

[1] Wang, F. C. and Marangoni, A. G. 2016. Advances in the Application of Food Emulsifier a-Gel Phases: Saturated Monoglycerides, Polyglycerol Fatty Acid Esters, and their Derivatives. Journal of Colloid and Interface Science. 483: 394-403.

DOI: http://dx.doi.org/10.1016/j.jcis.2016.08.012.

[2] Naik, M. K., Naik, S. N., and Mohanty, S. 2014. Enzymatic Glycerolysis for Conversion of Sunflower Oil to Food Based Emulsifiers. Catalysis Today. 237: 145-149. DOI: http://dx.doi.org/10.1016/j.cattod.2013.11.005.

[3] Ferretti, C. A., Fuente, S., Ferullo, R., Castellani, N., Apesteguía, C. R., and Di Cosimo, J. I. 2012 Monoglyceride Synthesis by Glycerolysis of Methyl Oleate 
on MgO: Catalytic and DFT Study of the Active Site. Applied Catalysis A: General. 413-414: 322-331.

DOI: http://dx.doi.org/10.1016/j.apcata.2011.11.025.

[4] Belelli, P. G., Ferretti, C. A., Apesteguía, C. R., Ferullo, R. M. and Di Cosimo, J. I. 2015. Glycerolysis of Methyl Oleate on MgO: Experimental and Theoretical Study of the Reaction Selectivity. Journal of Catalysis. 323: 132-144. DOI: http://dx.doi.org/10.1016/j.jcat.2015.01.001

[5] Miao, S. and Lin, D. 2019. Monoglycerides: Categories, Structures, Properties, Preparations, and Applications in the Food Industry. Encyclopedia of Food Chemistry. 155163.

DOI: http://dx.doi.org/10.1016/b978-0-08-100596-5.21595-3.

[6] Freitas, L., Paula, A. V., dos Santos, J. C., Zanin, G. M., and de Castro, H. F. 2010. Enzymatic Synthesis of Monoglycerides by Esterification Reaction Using Penicillium camembertii Lipase Immobilized on Epoxy SiO2-PVA Composite. Journal of Molecular Catalysis B: Enzymatic. 65(1-4): 87-90. DOl: http://dx.doi.org/10.1016/j.molcatb.2009.12.009.

[7] Siri-nguan, N. and Ngamcharussrivichai, C. 2016. Alkoxideintercalated $\mathrm{Mg}-\mathrm{Al}$ Layered Double Hydroxides as Selective Catalysts for the Synthesis of Monoglycerides. Reaction Kinetics, Mechanisms and Catalysis. 119(1): 273289.

DOI: http://dx.doi.org/10.1007/s11144-016-1018-5.

[8] Buchori, L., Istadi, I., and Purwanto, P. 2016. Advanced Chemical Reactor Technologies for Biodiesel Production from Vegetable Oils - A Review. Bulletin of Chemical Reaction Engineering \& Catalysis. 11 (3): 406-430. DOI: http://dx.doi.org/10.9767/bcrec.1 1.3.490.406-430.

[9] Kore, P. P., Kachare, S. D., Kshirsagar, S. S., and Oswal, R. J. 2012. Base Catalyzed Glycerolysis of Ethyl Acetate. Organic Chemistry Current Research. 1(4): 108-111. DOI: http://dx.doi.org/10.4172/2161-0401.1000108.

[10] Satriana, Arpi, N., Lubis, Y. M., Adisalamun, Supardan, M. D., and Mustapha, W. A. W. 2016. Diacylglycerol-enriched Oil Production Using Chemical Glycerolysis. Europian Journal of Lipid Science and Technology. 118(12): 18801890. DOI: http://dx.doi.org/10.1002/ejlt.201500489.

[11] Schulz, G. A. S., da Silveira, K. C., Libardi, D. B., Peralba, M. do. C. R., and Samios D. 2011. Synthesis and Characterization of Mono-acylglycerols through the Glycerolysis of Methyl Esters Obtained from Linseed Oil. Europian Journal of Lipid Science and Technology. 113(12): 1533-1540. DOI: http://dx.doi.org/10.1002/ejlt.201100079.

[12] Taufiq-Yap, Y. H., Lee, H. V., Hussein, M. Z., and Yunus, R. 2011. Calcium-based Mixed Oxide Catalysts for Methanolysis of Jatropha Curcas Oil to Biodiesel. Biomass and Bioenergy. 35(2): 827-834.

DOl: http://dx.doi.org/10.1016/j.biombioe.2010.11.011.

[13] Hoo, P. and Abdullah, A. Z. 2016. Monolaurin Yield Optimization in Selective Esterification of Glycerol with Lauric Acid over Post Impregnated HPW/SBA-15 Catalyst. Korean Journal of Chemical Engineering. 33(4): 1200-1210. DOI: http://dx.doi.org/10.1007/s1 1814-015-0246-0.

[14] Temelli, F., King, J. W., and List, G. R. 1996. Conversion of Oils to Monoglycerides by Glycerolysis in Supercritical Carbon Dioxide Media. Journal of the American Oil Chemists' Society. 73(6): 699-706.
DOI: http://dx.doi.org/10.1007/BF02517943.

[15] Anggoro, D. D., Oktavianty, H., Kurniawan, B. P., and Daud, R. 2019. Optimization of Glycerol Monolaurate (GML) Synthesis from Glycerol and Lauric Acid Using Dealuminated Zeolite Y Catalyst. Jurnal Teknologi. 81 (4): 133-141. DOI: http://dx.doi.org/10.11113/jt.v81.13511.

[16] Yang, F., Xiang, W., Sun, X., WU, H., Li, T., and Long, L. 2014. A Novel Lipid Extraction Method from Wet Microalga Picochlorum sp. at Room Temperature. Marine Drugs. 12(3): 1258-1270. DOI: http://dx.doi.org/10.3390/md12031258.

[17] Yetilmezsoy, K., Demirel, S., and Vanderbei, R. J. 2009. Response Surface Modeling of $\mathrm{Pb}$ (II) Removal from Aqueous Solution by Pistacia vera L.: Box-Behnken Experimental Design. Journal of Hazardous Materials. 171(1-3): 551-562. DOI: http://dx.doi.org/10.1016/j.jhazmat.2009.06.035.

[18] Sangeetha, V., Sivakumar, V., Sudha, A., and Devi, K. P. 2014. Optimization of Process Parameters for COD Removal by Coagulation Treatment Using Box-Behnken Design. International Journal of Engineering and Technology. 6(2): 1053-1058.

[19] Sonntag, N. O. V. 1983. Glycerolysis of Fats and Methyl Esters-Status, Review and Critique. Journal of the American Oil Chemists' Society. 60(7): 1245-1249. DOI: http://dx.doi.org/10.1007/BF02634442.

[20] Hussain, K., Ismail, F., and Senu, N. 2016. Solving Directly Special Fourth-order Ordinary Differential Equations Using Runge-Kutta Type Method. Journal of Computational and Applied Mathematics. 306: 179-199. DOI: http://dx.doi.org/10.1016/j.cam.2016.04.002.

[21] Xuan, J., Zheng, X., and Hu, H. 2012. Active Sites of Supported KF Catalysts for Transesterification. Catalysis Communications. 28: 124-127.

DOI: http://dx.doi.org/10.1016/j.catcom.2012.08.032.

[22] Fregolente, L. V., Batistella, C. B., Filho, R. M., and Maciel, M. R. W. 2005. Response Surface Methodology Applied to Optimization of Distilled Monoglycerides Production. Journal of the American Oil Chemists' Society. 82(9): 673678.

DOI: http://dx.doi.org/10.1007/s1 1746-005-1127-9.

[23] Istadi, 1. and Amin, N. A. S. 2006. Optimization of Process Parameters and Catalyst Compositions in Carbon Dioxide Oxidative Coupling of Methane over $\mathrm{CaO}-\mathrm{MnO} / \mathrm{CeO}_{2}$ Catalyst Using Response Surface Methodology. Fuel Processing Technology. 87: 449-459. DOI: http://dx.doi.org/10.1016/j.fuproc.2005.11.004.

[24] Mustafa, M. N., Shafie, S., Wahid, M. H., and Sulaiman, Y. 2019. Optimization of Power Conversion Efficiency of Polyvinyl-Alcohol/Titanium Dioxide Compact Layer Using Response Surface Methodology/Central Composite Design. Solar Energy. 183: 689-696. DOI: http://dx.doi.org/10.1016/j.solener.2019.03.074

[25] Montgomery, D. C. 2001. Statis and Analysis of Experiments. Fifth Eds. United States of America: John Wiley \& Sons, Inc.

[26] Feuge, R. O. and Bailey, A. E. 1946. Modification of Vegetable Oils: VI. The Practical Preparation of Monoand Diglycerides. Oil \& Soap. 23(8): 259-264. DOI: http://dx.doi.org/10.1007/BF02696133. 